\title{
Longterm Safety and Efficacy of Tocilizumab in Patients with Rheumatoid Arthritis: A Cumulative Analysis of Up to 4.6 Years of Exposure
}

\author{
MARK C. GENOVESE, ANDREA RUBBERT-ROTH, JOSEF S. SMOLEN, JOEL KREMER, MAJED KHRAISHI, \\ JUAN GÓMEZ-REINO, ANTHONY SEBBA, ROBERT PILSON, SARAH WILLIAMS, and RONALD van VOLLENHOVEN
}

\begin{abstract}
Objective. To assess the longterm safety and efficacy of tocilizumab (TCZ) in patients with moderate to severe rheumatoid arthritis (RA).

Methods. Patient data were from 5 randomized controlled TCZ trials $(n=4211)$, their open-label extension phases $(n=3512)$, and a drug interaction study $(n=23)$. All randomly assigned patients, regardless of previous RA treatment, were analyzed. Measures of safety included number of adverse events (AE), serious AE (SAE), AE leading to treatment discontinuation, laboratory tests, and deaths. Efficacy measures included American College of Rheumatology (ACR) 20/50/70 responses, tender joint count (TJC), swollen joint count (SJC), ACR core set components, and low disease activity (LDA) or Disease Activity Score in 28 joints (DAS28) remission. ACR/European League Against Rheumatism (EULAR) disease remission was a posthoc exploratory analysis.

Results. Total duration of observation was 12,293 patient-years (PY). No new safety signals were identified; infections were the most common AE and SAE. The rate of serious infections was 4.5/100 PY. Improvements from baseline in clinical efficacy, measured as ACR20/50/70 responses, TJC, SJC, ACR core set components, and LDA and DAS28 remission, were generally sustained through at least 216 weeks of followup. ACR/EULAR disease remission was attained by $16.5 \%$ (Boolean) and $22.7 \%$ (index) of patients at Week 216.

Conclusion. TCZ has to date been studied for up to 4.6 years (240 weeks) of treatment in patients with RA. Our analysis reveals a longer-term safety profile consistent with previous observations, no new safety signals, and durable efficacy of TCZ in a large clinical trial program. (J Rheumatol First Release March 1 2013; doi:10.3899/jrheum.120687)
\end{abstract}

Key Indexing Terms:

TOCILIZUMAB TREATMENT EFFICACY SAFETY RHEUMATOID ARTHRITIS

Rheumatoid arthritis (RA) is an inflammatory disease characterized by progressive joint damage, functional impairment, and reduced health-related quality of

From the Division of Rheumatology, Stanford University Medical Center, Palo Alto, California, USA; Department of Internal Medicine, University of Cologne, Cologne, Germany; Division of Rheumatology, Department of Medicine III, Medical University of Vienna, Vienna, Austria; Center for Rheumatology, Albany Medical College, State University of New York, Albany, New York, USA; Memorial University of Newfoundland, St. John's, Newfoundland and Labrador, Canada; Rheumatology Unit Hospital, Clinical Universitario, Santiago, Spain; Department of Rheumatology, University of South Florida, Palm Harbor, Florida, USA; Hoffmann-La Roche Inc., Nutley, New Jersey, USA; PDBB-Biostatistics, Roche Products Limited, Welwyn Garden City, UK; and Rheumatology Unit, Department of Medicine, Karolinska University Hospital in Solna, Stockholm, Sweden.

Funding for manuscript preparation was provided by F. Hoffmann-La Roche Ltd. Dr. Genovese has received grant support and consulting revenue from Roche. Dr. Rubbert-Roth has received grant support from and has served on the speakers bureau for Roche. Dr. Smolen has received grant support and consulting revenue from and has served on the speakers bureau for Roche. Dr. Kremer has received grant support and consulting revenue from and has served on the speakers bureau for Genentech, a member of the Roche group. Dr. Khraishi has received grant support from Roche Canada and has served on the speakers bureau for Roche. Dr. Gomez-Reino has received research grant support and consulting revenue from Roche. Dr. Sebba has received consulting revenue from and has served on the speakers bureau for Genentech, a member of the Roche life $\mathrm{e}^{1,2,3,4,5}$. Tocilizumab (TCZ) is a humanized monoclonal antibody that inhibits interleukin 6 (IL-6) binding to soluble and membrane-expressed receptors and blocks IL-6

group. Dr. Pilson was an employee of Hoffmann-La Roche Inc. Ms. Williams is an employee of Roche Products Ltd. Dr. van Vollenhoven has received grant support, consulting revenue, and honoraria from Roche. M.C. Genovese, MD, Professor, Division of Rheumatology, Stanford University Medical Center; A. Rubbert-Roth, PhD, Professor, Department of Internal Medicine, University of Cologne; J.S. Smolen, MD, Professor, Division of Rheumatology, Department of Medicine III, Medical University of Vienna; J. Kremer, MD, Professor, Center for Rheumatology, Albany Medical College, State University of New York; M. Khraishi, MBBCh, FRCPC, Clinical Professor of Medicine (Rheumatology), Co-chair Human Investigation Committee, Memorial University of Newfoundland; J. Gómez-Reino, MD, Professor of Medicine, Head, Rheumatology Unit, Hospital Clinical Universitario; A. Sebba, MD, Assistant Clinical Professor, Department of Rheumatology, University of South Florida; R. Pilson, MS, Clinical Science Associate, Product Development, Immunology, Hoffmann-La Roche Inc.; S. Williams, MSc, Senior Statistical Scientist, PDBB-Biostatistics, Roche Products Limited; R. van Vollenhoven, MD, PhD, Senior Physician, Associate Professor, Rheumatology Unit, Department of Medicine, Karolinska University Hospital in Solna.

Address correspondence to Prof. M.C. Genovese, Division of Rheumatology, Stanford University Medical Center, Palo Alto, CA 94304, USA.E-mail: Genovese@stanford.edu

Accepted for publication December 11, 2012. 
receptor signaling ${ }^{6}$. Five international, phase III, randomized, placebo-controlled clinical trials (RCT) of 24 weeks' $7,8,9,10$ and 52 weeks' ${ }^{11}$ duration showed evidence that TCZ, given as monotherapy or in combination with methotrexate (MTX) or other disease-modifying antirheumatic drugs (DMARD), reduces signs and symptoms of RA, inhibits radiographic progression, and improves patient function. These studies demonstrated a consistent safety profile for TCZ across different patient populations, including patients who had not been exposed or had inadequate responses to MTX treatment ${ }^{10}$ and patients who had inadequate responses to tumor necrosis factor inhibitors $\left(\text { TNF-IR) }{ }^{9} \text { or DMARD (DMARD-IR) }\right)^{7,8,11}$.

Assessment of the longterm safety and efficacy of TCZ increases the body of information available about the drug. A 5-year open-label extension of a 3-month, double-blind RCT showed evidence of the longterm safety and efficacy of TCZ monotherapy in Japanese DMARD-IR patients ${ }^{12}$. Most recently, Schiff, et $a l^{13}$ conducted an integrated safety analysis of TCZ therapy from the 5 phase III clinical trials $\mathrm{s}^{7,8,9,10,11}$ and their open-label extensions. In that analysis, the mean duration of treatment was 2.4 years, and the duration of observation was 9414 patient-years $(\mathrm{PY})^{13}$. Results showed that the safety profile of TCZ over 2.4 years was consistent with that observed in the phase III studies.

We present evidence of the longterm safety and efficacy of TCZ in patients with moderate to severe RA, based on an analysis that includes 12,293 PY of observation. To our knowledge, this is the first report to assess the longterm safety and efficacy of TCZ in patients outside Japan.

\section{MATERIALS AND METHODS}

Patient data sources. Patient data were pooled from 5 phase III RCT [OPTION (in MTX-IR) ${ }^{7}$, TOWARD (in DMARD-IR) ${ }^{8}$, RADIATE (in antiTNF-IR) ${ }^{9}$, AMBITION (TCZ monotherapy study in patients who were MTX-naive or who had not previously failed MTX) ${ }^{10}$, and LITHE (structural damage/radiographic study in MTX inadequate responders) ${ }^{11}$ ], their ongoing extension trials (GROWTH95, GROWTH96, and the open-label extension phase of LITHE), and an open-label, randomized, drug interaction study ${ }^{14}$ (Table 1).

TCZ treatment. In the $5 \mathrm{TCZ}$ RCT, patients were initially randomly assigned to receive placebo or intravenous TCZ ( 4 or $8 \mathrm{mg} / \mathrm{kg}$ ) alone or in combination with MTX/DMARD.

The drug interaction study consisted of patients $(n=23)$ who received a single dose of TCZ $10 \mathrm{mg} / \mathrm{kg}$ and were assessed for safety but not for efficacy.

On entering the open-label extension trials, all patients received 8 $\mathrm{mg} / \mathrm{kg}$ TCZ. Investigators were permitted to modify the dose of TCZ (e.g., to reduce temporarily to $4 \mathrm{mg} / \mathrm{kg}$ or skip doses entirely) as clinically required for safety reasons according to the clinical trial protocols. Baseline was defined as the first time a patient received TCZ as initial or rescue therapy. Baselines were staggered, and the numbers of patients with assessments decreased over time because some patients had not yet reached later assessments or had withdrawn from the study.

Safety populations. Safety was evaluated in 2 patient populations - the all-control population and the all-exposed population. In total, 4211 patients were randomly assigned to TCZ or placebo in the $5 \mathrm{RCT}^{7,8,9,10,11}$. The all-control population included data from the double-blind treatment phases of each of the 5 RCT studies $7,8,9,10,11$, from randomization until the first change in treatment (on initiation of rescue therapy or entry into an open-label extension), or until 2 years' study duration (LITHE) was reached. Data for the all-control population are presented by initially randomized treatment group. The all-exposed population included all patients who received at least 1 dose of TCZ from their first dose (in 1 of the 5 RCT as initial therapy or rescue therapy, in an open-label extension study, or in the drug interaction study) to the cutoff date of February 17, 2010.

Efficacy populations. The efficacy population comprised all patients who received at least 1 dose of TCZ in the $5 \mathrm{RCT}$ and/or in the open-label extensions until the cutoff date of February 17, 2010. Patients from the drug interaction study were excluded. Data for patients who received TCZ (4 or $8 \mathrm{mg} / \mathrm{kg}$ ) were pooled into a single TCZ group. Efficacy analyses summarize outcomes for each of 3 patient populations who entered open-label extensions: (1) the never-exposed (NE) or never-failed (NF) MTX (NE/NF MTX) group included patients with active RA who were initially enrolled in AMBITION. These patients were naive to biologic therapy and MTX (or had not received MTX within 6 months before study start) and had never discontinued MTX because of adverse events (AE) or lack of efficacy; (2) the DMARD-IR group included patients initially enrolled in OPTION, TOWARD, and LITHE; and (3) the TNF-IR group included patients initially enrolled in RADIATE.

Assessments. The extent of TCZ exposure was calculated by assigning 28 days to each infusion received. Total duration of observation was defined as the time from the first TCZ dose to the last safety observation, regardless of whether this observation was reported within 28 days of the last TCZ dose, and was the denominator for patient-adjusted $\mathrm{AE}$ rates.

Safety and laboratory assessments. Measures of safety, including AE, serious $\mathrm{AE}$ (SAE), AE leading to treatment discontinuation or dose modification, and deaths, were recorded. AE and SAE per system organ class and rates of death were expressed per $100 \mathrm{PY}$ and were calculated overall and in 12-month periods for the all-exposed population and by treatment group for the all-control population. AE by intensity, serious infectious events, and $\mathrm{AE}$ leading to dose modification or withdrawal were also recorded. Multiple occurrences of the same AE in a patient were counted once for that patient. Rates of withdrawal from treatment for safety reasons and nonsafety reasons were recorded for the all-exposed safety population. Neutrophil and platelet counts, hepatic transaminases [alanine aminotransferase (ALT) and aspartate aminotransferase (AST)], and lipid levels were monitored by routine laboratory tests performed at scheduled visits.

Efficacy assessments. Planned efficacy assessments included American College of Rheumatology (ACR) 20/50/70 responses; summary of swollen joint count (SJC) and tender joint count (TJC) by visit; low disease activity (LDA), defined as Disease Activity Score in 28 joints (DAS28) $\leq 3.2$; DAS28 remission [DAS28 < 2.6; calculated with erythrocyte sedimentation rate (ESR)]; Health Assessment Questionnaire-Disability Index (HAQ-DI) categorical change from baseline (improved, $\leq-0.5$; unchanged, $>-0.5$ to $<0.5$; or worsened, $\geq 0.5$ ); and withdrawal reasons by 48 -week periods. Posthoc exploratory analyses included disease remission according to the 2011 ACR/European League Against Rheumatism (EULAR) Boolean-based definition [i.e., scores for TJC, SJC, C-reactive protein $(\mathrm{CRP}, \mathrm{mg} / \mathrm{dl})$, and Patient Global Assessment of Disease Activity score $(0-10$ scale, all $\leq 1)$ ] and the index-based definition [Simplified Disease Activity Index $(\mathrm{SDAI}) \leq 3.3$ ] at various timepoints ${ }^{15}$, ACR20 responders at Week 12 who then achieved ACR50/70 response over time, and patients who had LDA at Week 12 and achieved DAS28 remission over time.

Timing of assessments. Safety was monitored throughout the trials. Efficacy assessments occurred every 4 weeks in OPTION, TOWARD, RADIATE, and AMBITION and in years 1 and 2 of LITHE, every 8 weeks in years 3 to 5 of $\operatorname{LITHE}^{7,8,9,10,11}$, and every 12 weeks in the open-label extensions until the cutoff date. Data for summaries were assigned to the nearest 12 -week timepoint for pooling. Sufficient data [i.e., $\geq 10 \%$ of the number of patients $(n)$ originally included in each group at baseline $(\mathrm{N})$ ] were 
Table 1. Study design and treatment features of tocilizumab phase III randomized controlled trials and open-label extensions.

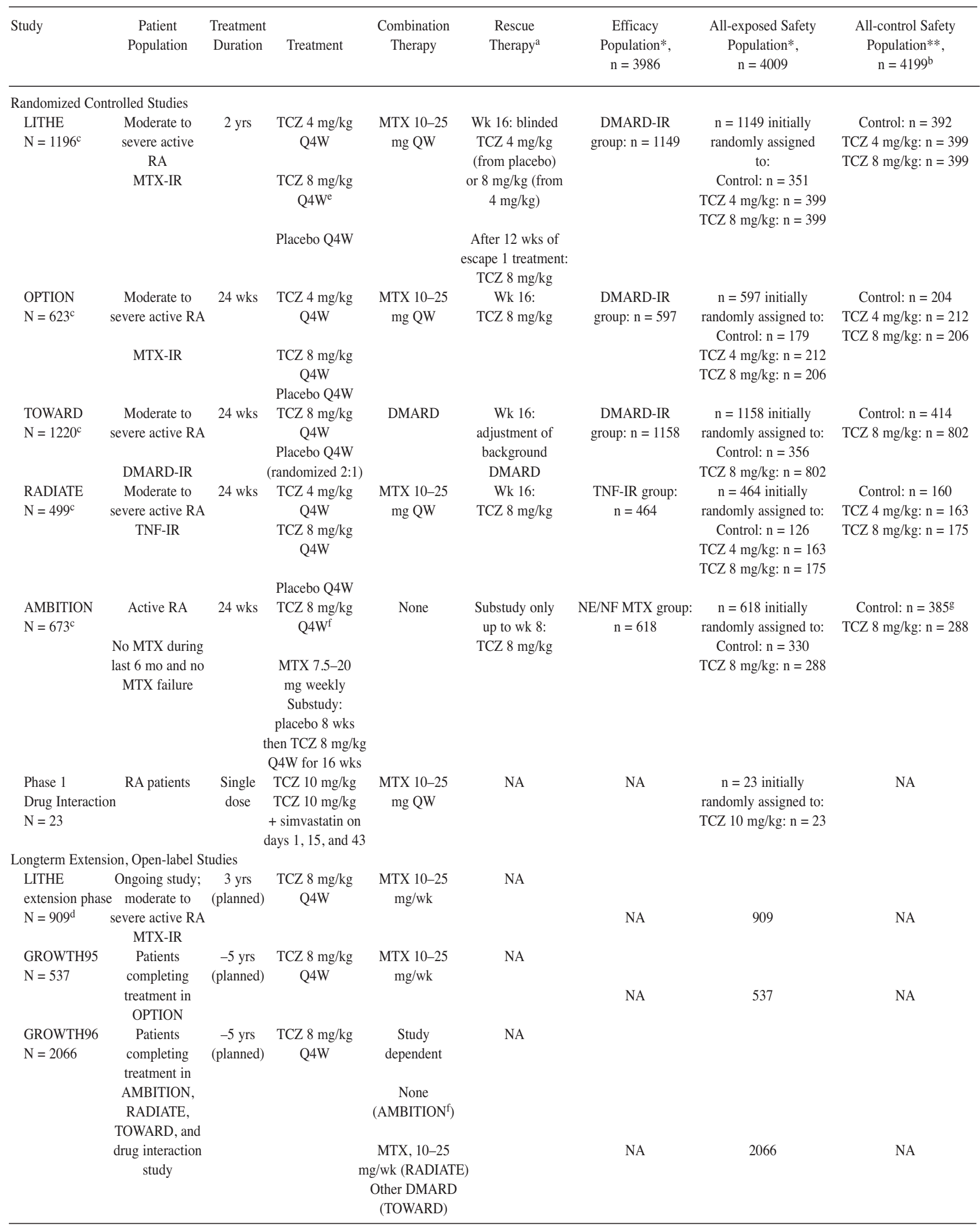


* TCZ-treated patients (from controlled and extension studies). $* *$ TCZ- or control-treated (from controlled studies). ${ }^{\text {a }}$ Patients who did not attain $20 \%$ improvement in swollen joint count (SJC) or tender joint count (TJC) could receive rescue therapy during the randomized phase. ${ }^{b}$ Does not include 23 patients from the phase I clinical pharmacology study and 12 patients initially randomly assigned in the randomized controlled studies who did not receive study treatment: LITHE $(\mathrm{n}=6)$, OPTION $(\mathrm{n}=1)$, TOWARD $(\mathrm{n}=$ 4), and RADIATE $(n=1) .{ }^{c}$ No. patients randomly assigned during phase III study. ${ }^{d}$ Estimated no. patients who entered extension phase (study is ongoing; final data not available). ${ }^{\mathrm{e}}$ At Week 52, all patients were required to start open-label TCZ $8 \mathrm{mg} / \mathrm{kg}$ for Year 2 unless they had attained $\geq 70 \%$ improvement in SJC and TJC, allowing them to continue the blinded therapy they were receiving at the end of Year 1 to Week 104. ${ }^{\mathrm{f}}$ Patients who attained $\geq 50 \%$ reduction in TJC and SJC (assessed from baseline) while receiving initially randomized study treatment at weeks 20 and 24 could opt to continue their current blinded treatment in a transition phase that lasted until the last patient enrolled in AMBITION completed the 24-week randomized phase of the study; 234 AMBITION patients continued to receive TCZ 8 mg/kg monotherapy for all evaluations. g 284 patients from blinded study; 101 patients from placebo substudy. DMARD: disease-modifying antirheumatic drug; IR: inadequate response; MTX: methotrexate; NA: not applicable; NE/NF: never exposed/never failed; QW: once every week; Q4W: once every 4 weeks; RA: rheumatoid arthritis; SJC: swollen joint count; TCZ: tocilizumab; TJC: tender joint count; TNF: tumor necrosis factor.

available to provide assessments up to Week 240 ( 4.6 years) for the DMARD-IR group and up to Week 216 for the NE/NF MTX and TNF-IR groups.

Statistical analyses and handling of missing data. All outcomes were summarized descriptively. Efficacy data were included in the analyses when sufficient data (defined above) were available. Efficacy analyses were based on available patient assessments at each timepoint. The number of patients with data available for each assessment at each timepoint decreased over time because some patients had not yet reached that point in their treatment or had withdrawn from the study.

The last observation carried forward method was used for TJC and SJC calculations. No imputation was used for missing HAQ-DI score, CRP, ESR, or visual analog scale (VAS) assessments. CRP was used primarily for calculation of ACR response; if missing, ESR was used. For DAS28 remission calculations, no substitute was used for a missing ESR value.

\section{RESULTS}

Patient populations. In total, 4211 patients were enrolled in the $5 \mathrm{RCT}$, and 23 patients were enrolled in the drug interaction study. Twelve patients did not receive any randomized study treatment. Among the 4199 patients in the all-control population, 1555 were initially randomly assigned to a control group (placebo \pm MTX or placebo \pm other DMARD), 774 were initially randomly assigned to 4 $\mathrm{mg} / \mathrm{kg}$ TCZ + DMARD, and 1870 were initially randomly assigned to $8 \mathrm{mg} / \mathrm{kg}$ TCZ + DMARD. Corresponding durations of observation at the data cutoff date were 824.6 PY, 564.5 PY, and 1194.1 PY, respectively. Of these, 3512 patients participated in the corresponding open-label extensions (Table 1).

The all-exposed population included 4009 patients who received at least $1 \mathrm{TCZ}$ dose. At the data cutoff date, mean duration of TCZ treatment was 3.07 years (up to 4.6 years); total duration of observation was 12,293 PY.

Among the 3986 patients in the efficacy population, 1342 were initially randomly assigned to the control group (placebo \pm MTX or placebo \pm other DMARD), 774 were initially randomly assigned to $4 \mathrm{mg} / \mathrm{kg}$ TCZ, and 1870 were initially randomly assigned to $8 \mathrm{mg} / \mathrm{kg}$ TCZ. In total, $684 \mathrm{of}$ 3986 patients received rescue therapy (TCZ 4 or $8 \mathrm{mg} / \mathrm{kg}$ ). Of these 684 patients, 386, 166, and 132 were initially randomly assigned to placebo, $4 \mathrm{mg} / \mathrm{kg}$ TCZ, and $8 \mathrm{mg} / \mathrm{kg}$ TCZ, respectively. Only the LITHE study allowed stepwise rescue therapy (i.e., $4 \mathrm{mg} / \mathrm{kg}$ TCZ, then $8 \mathrm{mg} / \mathrm{kg}$ TCZ) for patients initially randomly assigned to placebo; consequently, 30 patients initially randomly assigned to placebo received stepwise rescue therapy. Within the efficacy population, the NE/NF MTX group comprised 618 patients. The DMARD-IR group comprised 2904 patients, and the TNF-IR group comprised 464 patients.

Safety outcomes: rates of withdrawal. In the all-control population, rates of withdrawal attributed to $\mathrm{AE}$ were 6.9/100 PY in the control group, $10.1 / 100 \mathrm{PY}$ in the $4 \mathrm{mg} / \mathrm{kg}$ TCZ group, and $10.2 / 100 \mathrm{PY}$ in the $8 \mathrm{mg} / \mathrm{kg}$ TCZ group (Table 2). A Kaplan-Meier plot over time is shown in Figure 1. In the all-exposed population, the overall rate of withdrawal attributed to AE was 5.2/100 PY, with most withdrawals occurring during the first 12 months $(9.2 / 100$ PY; Table 2). The most common AE leading to withdrawal in the first 12 months were liver function test abnormalities at a rate of 2.4/100 PY. Overall, more patients withdrew from treatment for safety reasons $(16 \%)$ than because of insufficient therapeutic response $(4.3 \%)$. The proportion of patients who withdrew from treatment because of safety (AE or death) or nonsafety reasons (i.e., insufficient therapeutic response, refused treatment, did not cooperate, withdrew consent, failure to return, administrative/other, entry selection criteria violation, or other violations) was higher during the first 48 weeks $(6.8 \%$ and $6.4 \%$, respectively) than during Weeks 49 to 96 (3.9\% and 4.0), during Weeks 97 to 144 (2.6\% and 2.5\%), and past Week 144 (2.8\% and $2.1 \%$ ).

Rates of $A E$. Overall rates of AE were similar among the 3 treatment groups in the all-control population (339.0 to 381.6/100 PY) and during the first 12 months of treatment in the all-exposed population (379.4/100 PY; Table 2). Rates of SAE were also similar between active and control groups (13.6 to $14.5 / 100 \mathrm{PY}$ ) and during the first 12 months of treatment in the all-exposed population (15.5/100 PY). In the all-exposed population, rates of $\mathrm{AE}$ and $\mathrm{SAE}$ were highest during the first 12 months of treatment and declined thereafter.

Infection rates. In the all-exposed population, the rate of 


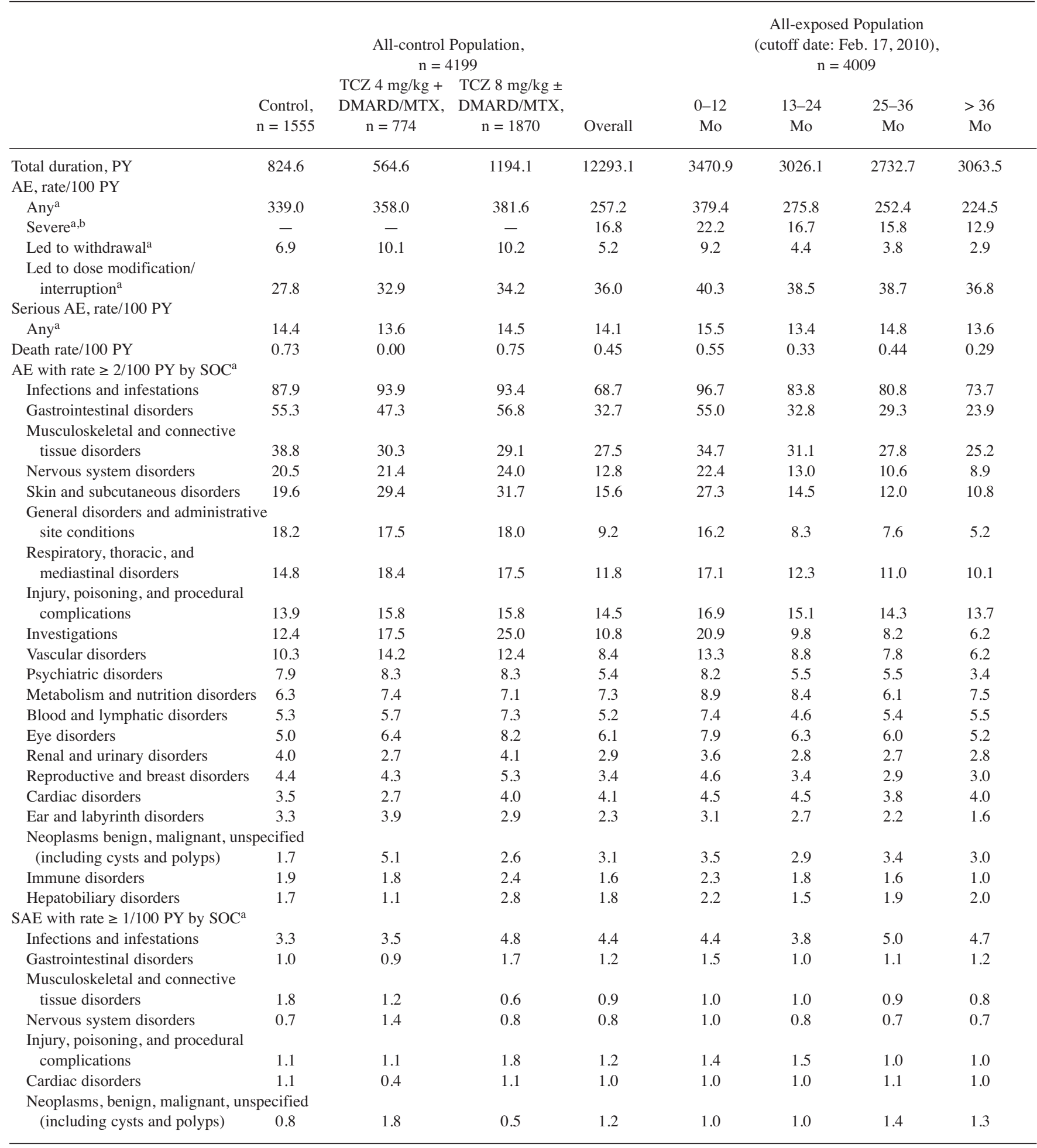

${ }^{\mathrm{a}}$ Multiple occurrences of the same AE in a patient are counted once in each period. ${ }^{\mathrm{b}}$ Intensity of AE graded by the investigator as mild, moderate, or severe. PY: patient-years; SAE: serious adverse event; SOC: system organ class; TCZ: tocilizumab; DMARD: disease-modifying antirheumatic drug; MTX: methotrexate.

serious infection was 4.5/100 PY. Pneumonia (0.7/100 PY) and cellulitis $(0.5 / 100 \mathrm{PY})$ were the most commonly reported. Serious infection rates appeared stable over time.
Nine cases of SAE opportunistic infections, excluding tuberculosis (TB), were reported. Eight of these 9 were previously described by Schiff, et $a l^{13}$. These 9 cases were 


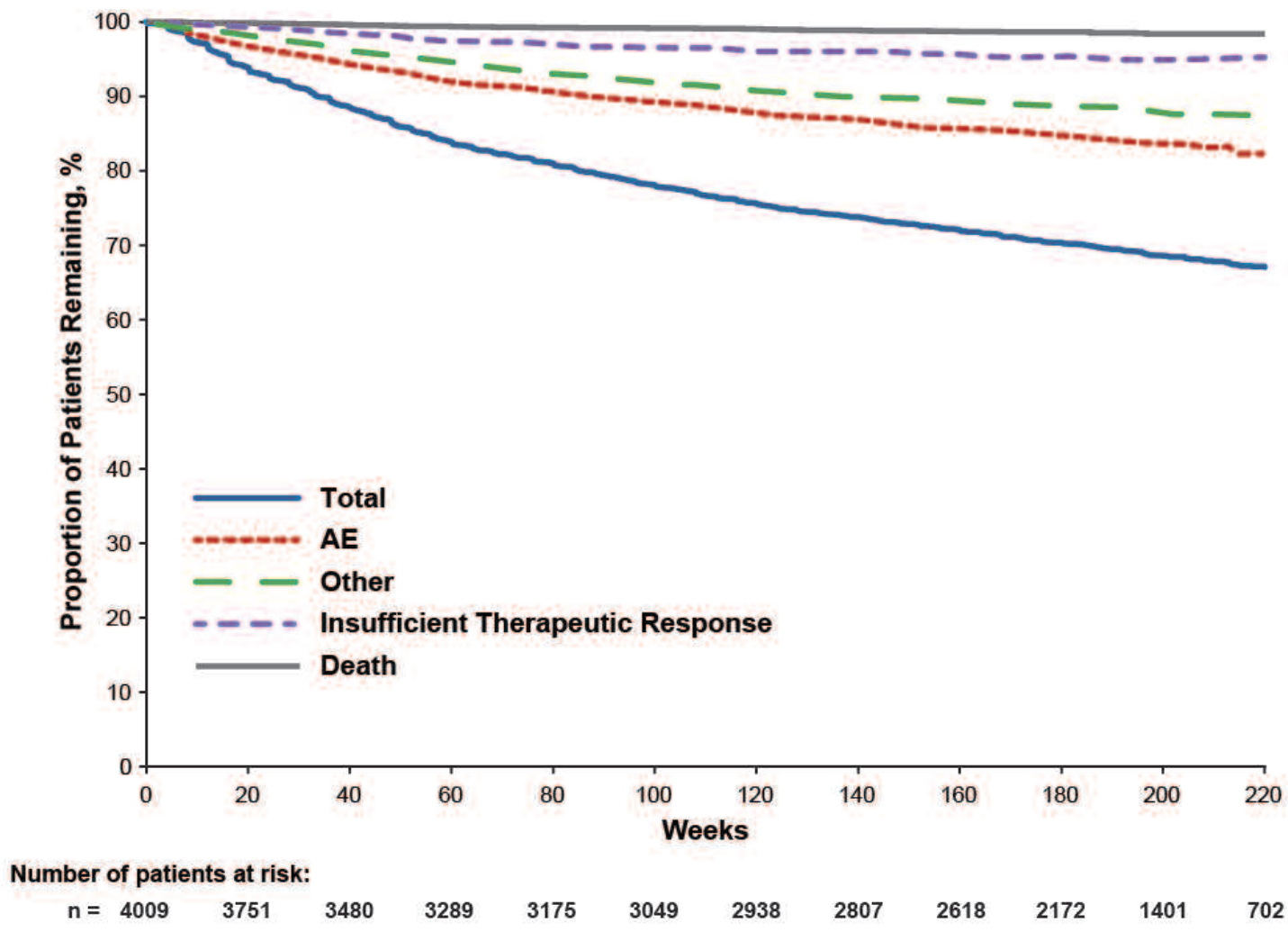

Figure 1. Kaplan-Meier plot of patient withdrawal by withdrawal reason (all-exposure population). AE: adverse event.

candidiasis ( 2 cases of systemic and 1 case of osteomyelitis), fungal sinusitis (1 case), non-TB mycobacterial infection (1 case), and 1 case each of Pneumocystis jiroveci pneumonia, cryptococcal pneumonia, Alcaligenes infection, and coccidioidomycosis (localized, nondisseminated). Of these 9 , there were 3 deaths, all in the patients with candidiasis.

Patients were screened for TB per the local standard of care. Patients with active TB were excluded, but those with latent TB received standard of care prophylaxis and could enter the study. Nine patients developed TB, for a rate of 0.1/100 PY. All TB cases except 1 appeared to be de novo; in that 1 case, a patient from Spain was treated for latent TB on study entry and developed pulmonary TB at Week 96. The patient was subsequently treated with anti-TB medication and improved. Of the patients who developed TB, 6 were taking concomitant corticosteroids; diagnoses of TB were made at variable times (range 39-202 weeks) from the start of TCZ treatment.

Cardiovascular and gastrointestinal perforation events. The rate of myocardial infarction was $0.29 / 100 \mathrm{PY}$, the rate of stroke was $0.16 / 100 \mathrm{PY}$, and the rate of gastrointestinal perforation was $0.2 / 100 \mathrm{PY}$. These rates are similar to those previously described ${ }^{13}$. There was no evidence of increased rates compared with those observed in epidemiologic studies of patients with $\mathrm{RA}^{16,17,18,19}$.
Malignancies. The overall rate of SAE malignancies was 1.2/100 PY. The most frequently reported were basal cell carcinoma at a rate of $0.1 / 100$ PY (9 events), uterine leiomyoma at a rate of $0.1 / 100$ PY ( 8 events), and breast cancer and prostate cancer ( 6 events each). The pattern of malignancies was as expected in the population studied, and rates were similar to those previously described ${ }^{13}$. For the subset of patients in the United States, standardized incidence rates (SIR) for malignancies were calculated using the US Surveillance and Epidemiology End Results 2000 rates for the general population as a reference. The SIR for malignancy was 1.050 (95\% CI 1.011-1.091), similar to that expected for the general population.

Hepatic events. Three cases of SAE hepatic disorders were reported: autoimmune hepatitis, hepatic steatosis, and ischemic hepatitis (1 each). The cases of autoimmune hepatitis and hepatic steatosis were not clearly related to TCZ; ischemic hepatitis occurred with an elevation of transaminase levels in a patient with anaphylaxis. Transaminase elevations are described below. To date, the elevations in transaminase levels seen with TCZ have not resulted in an increased rate of clinically relevant liver injury.

Deaths. In the all-control population, rates of death were $0.73 / 100 \mathrm{PY}$ in the control group, 0 in the $4 \mathrm{mg} / \mathrm{kg} \mathrm{TCZ}$ group, and 0.75 in the $8 \mathrm{mg} / \mathrm{kg}$ TCZ group (Table 2). In the all-exposed population overall, 55 deaths $(0.45 / 100$ PY) 
occurred $\leq 84$ days after the last dose. The most frequent causes of death in the all-exposed population were serious infection $(n=18)$, cardiac events $(n=12)$, malignancy $(n=$ $6)$, and respiratory events $(\mathrm{n}=5)$.

Laboratory measures. Laboratory measures for the all-control population were described previously ${ }^{13}$. In the all-exposed population, the mean neutrophil count was $5.8 \times$ $10^{9} / 1$ at baseline and decreased by about $2.0 \times 10^{9} / 1$ after the first infusion of TCZ; no systematic change was noted thereafter. Common toxicity criteria (CTC) for grade 3 neutropenia [absolute neutrophil count (ANC) 0.5 to $<1.0 \times$ $10^{9} / 1$ occurred in 192 of 4002 observed patients $(4.8 \%)$, and CTC grade 4 neutropenia (ANC $<0.5 \times 10^{9} / 1$ ) occurred in 30 of 4002 patients $(<1 \%)$. As described by Schiff, et $a l^{13}$, 1 patient experienced a serious infection of empyema temporally associated with grade 3 neutropenia. None of the patients with grade 4 neutropenia experienced serious

\section{A) NE/NF MTX Patients}

NE/NF MTX $(n=618)$

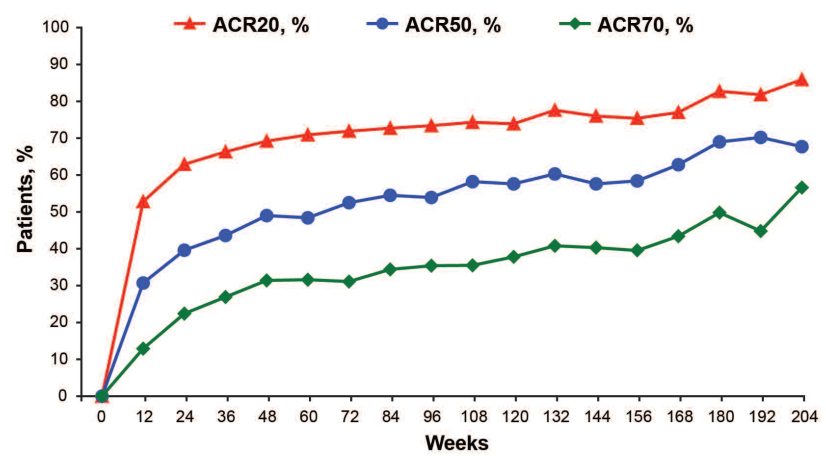

$\begin{array}{lllllllllllllllllll}\text { Week } & 0 & 12 & 24 & 36 & 48 & 60 & 72 & 84 & 96 & 108 & 120 & 132 & 144 & 156 & 168 & 180 & 192 & 204\end{array}$ $\begin{array}{lllllllllllllllllll}\mathrm{n} & 618 & 597 & 563 & 525 & 522 & 494 & 488 & 479 & 477 & 459 & 460 & 441 & 429 & 399 & 339 & 271 & 181 & 99\end{array}$ $\begin{array}{lllllllllllllllllll}\text { ACR20 } & - & 315 & 354 & 348 & 361 & 350 & 351 & 348 & 350 & 341 & 340 & 342 & 326 & 301 & 261 & 224 & 148 & 85\end{array}$ \begin{tabular}{llllllllllllllllllll}
\hline ACR50 & - & 183 & 223 & 229 & 256 & 239 & 256 & 261 & 257 & 267 & 265 & 266 & 247 & 233 & 213 & 187 & 127 & 67
\end{tabular} \begin{tabular}{lllllllllllllllllll}
\hline ACR70 & - & 77 & 126 & 141 & 164 & 156 & 152 & 165 & 169 & 163 & 174 & 180 & 173 & 158 & 147 & 135 & 81 & 56
\end{tabular}

C) TNF-IR Patients

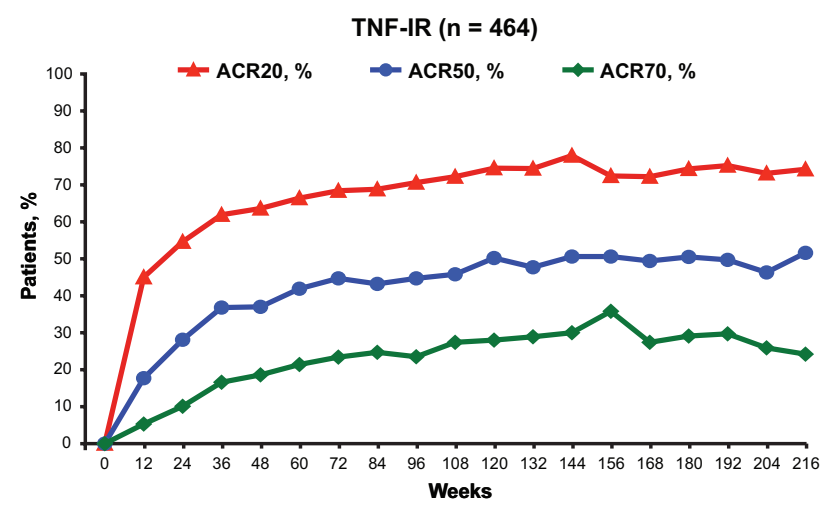

\begin{tabular}{llllllllllllllllllll} 
Week & 0 & 12 & 24 & 36 & 48 & 60 & 72 & 84 & 96 & 108 & 120 & 132 & 144 & 156 & 168 & 180 & 192 & 204 & 216 \\
\hline & 464 & 53 & 405 & 367 & 354 & 327 & 320 & 308 & 293 & 288 & 275 & 266 & 263 & 257 & 237 & 206 & 165 & 108 & 62
\end{tabular}

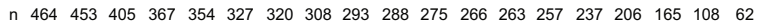
\begin{tabular}{lllllllllllllllllllll}
\hline ACR20 & - & 204 & 221 & 227 & 225 & 217 & 219 & 212 & 207 & 208 & 205 & 198 & 205 & 186 & 171 & 153 & 124 & 79 & 46 \\
\hline ACR50
\end{tabular} \begin{tabular}{lllllllllllllllllllll}
\hline ACR50 & - & 80 & 114 & 135 & 131 & 137 & 143 & 133 & 131 & 132 & 138 & 127 & 133 & 130 & 117 & 104 & 82 & 50 & 32 \\
\hline ACR70 & - & 24 & 41 & 61 & 6 & 70 & 75 & 76 & 69 & 79 & 77 & 77 & 79 & 92 & 65 & 60 & 49 & 28 & 15
\end{tabular}

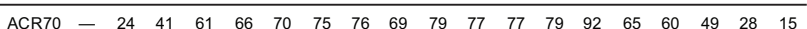

infection within 30 days of observed neutropenia. Fifteen patients $(<1 \%)$ had grade 3 thrombocytopenia $(\geq 25$ to $<50$ $\left.\times 10^{9} / 1\right)$, and 14 patients $(<1 \%)$ had grade 4 thrombocytopenia $\left(<25 \times 10^{9} / \mathrm{l}\right)$ at any time. As described, 1 serious bleeding event of hemorrhagic stomatitis occurred in a patient with CTC grade 4 thrombocytopenia ${ }^{13}$. The $8 \mathrm{mg} / \mathrm{kg}$ dose was maintained, and the event resolved without sequelae. No additional temporally associated serious infections or serious bleeding events were associated with these decreases. Total cholesterol, low-density lipoprotein (LDL), high-density lipoprotein (HDL), and triglyceride levels increased by the first assessment (Week 6) and remained relatively stable at subsequent timepoints. ALT and AST levels increased from normal at baseline to $>3$ times the upper limit of normal in $10.8 \%$ and $3.4 \%$ of patients, respectively. Overall, mean ALT, AST, and indirect and total bilirubin values increased from baseline in TCZ-treated

\section{B) DMARD-IR Patients}

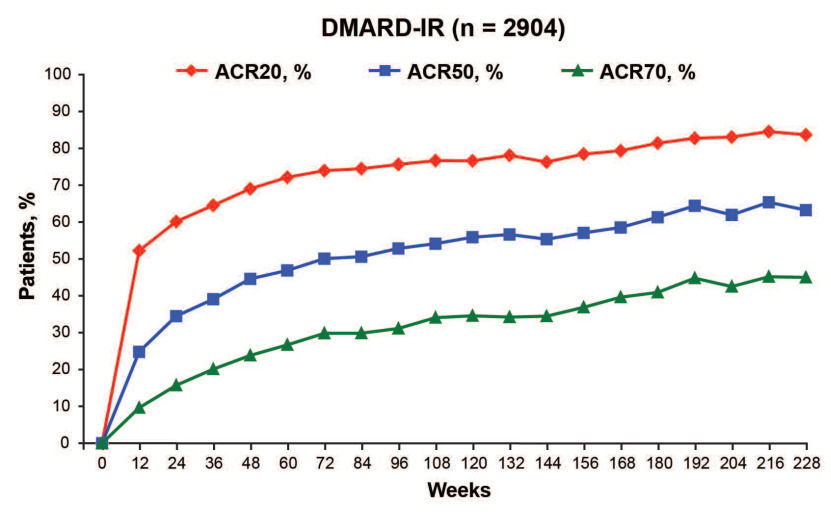

$\begin{array}{lllllllllllllllllllll}\text { Week } & 0 & 12 & 24 & 36 & 48 & 60 & 72 & 84 & 96 & 108 & 120 & 132 & 144 & 156 & 168 & 180 & 192 & 204 & 216 & 228\end{array}$ n $290428492693249324392376232022742242216620972048198719501797163713041028693 \quad 460$ ACR20 - $1488162016091684171417161694169616611607160015161530142613331079854586 \quad 385$ ACR50 - $707929974108811141162115111851173117211601100111310521004840637453 \quad 291$ \begin{tabular}{lllllllllllllllllllll}
\hline ACR70 & - & 274 & 423 & 501 & 581 & 634 & 692 & 679 & 698 & 738 & 725 & 701 & 685 & 719 & 712 & 670 & 584 & 437 & 313 & 207
\end{tabular}

Figure 2. Proportions of patients who achieved ACR20/50/70 responses during longterm treatment with TCZ. (A) NE/NF MTX group. (B) DMARD-IR group. (C) TNF-IR group. Data are shown only for weeks containing $\geq 10 \%$ of patients originally included in each group at baseline. Last observation carried forward method was used for tender and swollen joint counts. No imputation was used for missing HAQ score, CRP, ESR, or visual analog scale assessments. CRP was used primarily for calculation of ACR response; if missing, ESR was used. Analysis was performed in successful completers, defined as patients who reached each timepoint. The number of patients with assessments decreased over time because some patients had not yet reached later assessments or had withdrawn. Patients who withdrew were classified as missing, and missing data were excluded from summary statistics. ACR: American College of Rheumatology; CRP: C-reactive protein; DAS28: Disease Activity Score at 28 joints; DMARD: disease-modifying antirheumatic drug; ESR: erythrocyte sedimentation rate; IR: inadequate response; LDA: low disease activity; MTX: methotrexate; NE/NF: never exposed/never failed; TNF: tumor necrosis factor; TCZ: tocilizumab. 
patients as early as Week 2 by a mean of $18 \mathrm{U} / 1$ (range -244 to $307 \mathrm{U} / \mathrm{l}$ ), $8 \mathrm{U} / 1$ (range -95 to $169 \mathrm{U} / \mathrm{l}$ ), $1 \mu \mathrm{mol} / 1$ (range -11 to $19 \mu \mathrm{mol} / \mathrm{l}$ ), and $1 \mu \mathrm{mol} / 1$ (range -14 to $20 \mu \mathrm{mol} / \mathrm{l}$ ), and subsequently remained stable.

Efficacy outcomes. An analysis of observed patients was performed at each visit to assess improvements in ACR20/50/70 responses. Results showed that, after an increase in response rates at Week 12, the proportion of patients with improvements remained stable or continued to increase until the end of the evaluable assessment period in all patient populations. ACR20/50/70 responses were $85.9 \%, 67.7 \%$, and $56.6 \%$ in the NE/NF MTX group at Week 204 (Figure 2A); 83.7\%, 63.3\%, and $45.0 \%$ in the DMARD-IR group at Week 228 (Figure 2B); and 74.2\%, $51.6 \%$, and $24.2 \%$ in the TNF-IR group at Week 216 (Figure 2C). Despite the decreasing number of patients over time (e.g., 2904 at baseline but 2242 at Week 96 in the

\section{A) NE/NF MTX Patients}

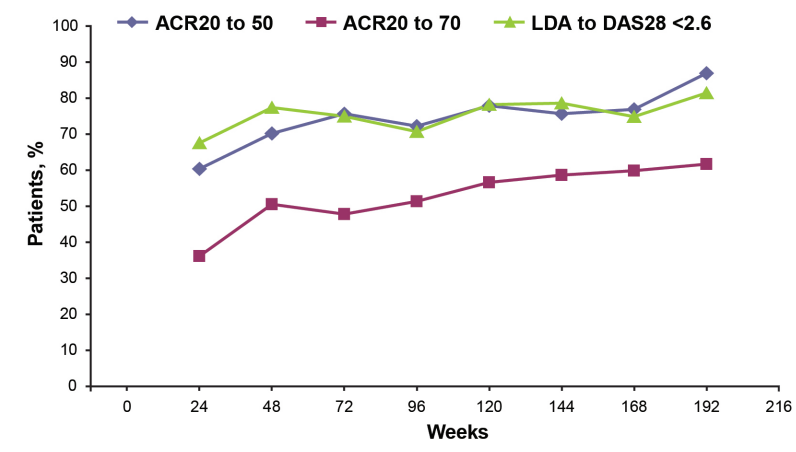

\begin{tabular}{rlllllllll} 
ACR20 responders, $\mathbf{N}$ & $\mathbf{3 0 2}$ & $\mathbf{2 8 5}$ & $\mathbf{2 6 8}$ & $\mathbf{2 6 3}$ & $\mathbf{2 5 8}$ & $\mathbf{2 3 9}$ & $\mathbf{1 9 9}$ & $\mathbf{1 0 7}$ & $\mathbf{2 4}$ \\
\hline ACR20 to $50(\mathrm{n})$ & $\mathbf{1 8 2}$ & 200 & 203 & 190 & 201 & 181 & 153 & 93 & 20 \\
\hline ACR20 to $70(\mathrm{n})$ & 109 & 144 & 128 & 135 & 146 & 140 & 119 & 66 & 18 \\
\hline LDA responders, $\mathbf{N}$ & $\mathbf{2 3 1}$ & $\mathbf{2 1 2}$ & $\mathbf{1 9 5}$ & $\mathbf{1 9 1}$ & $\mathbf{1 8 8}$ & $\mathbf{1 6 8}$ & $\mathbf{1 2 7}$ & $\mathbf{5 9}$ & $\mathbf{1 5}$ \\
\hline LDA to DAS28 $<2.6(\mathrm{n})$ & 156 & 164 & 146 & 135 & 147 & 132 & 95 & 48 & 11
\end{tabular}

C) TNF-IR Patients

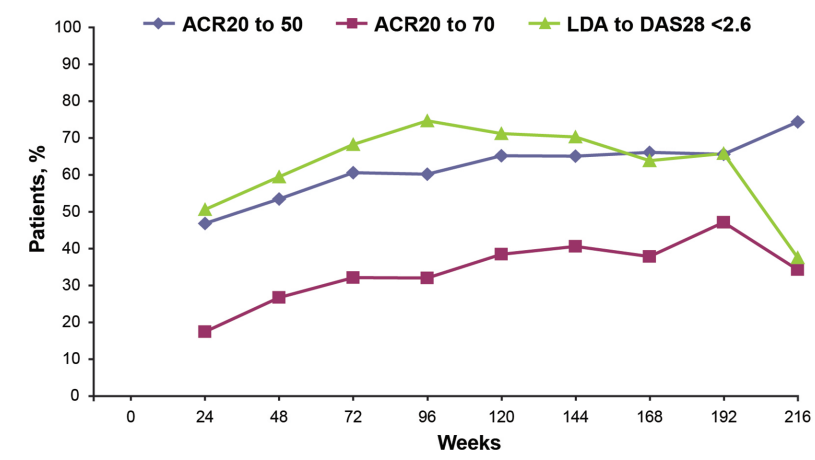

\begin{tabular}{rlllllllll} 
ACR20 responders, $\mathrm{N}$ & $\mathbf{1 9 0}$ & $\mathbf{1 7 6}$ & $\mathbf{1 6 2}$ & $\mathbf{1 5 3}$ & $\mathbf{1 4 6}$ & $\mathbf{1 4 3}$ & $\mathbf{1 2 7}$ & $\mathbf{8 7}$ & $\mathbf{3 5}$ \\
\hline ACR20 to $50(\mathrm{n})$ & 89 & 94 & 98 & 92 & 95 & 93 & 84 & 57 & 26 \\
\hline ACR20 to $70(\mathrm{n})$ & 33 & 47 & 52 & 49 & 56 & 58 & 48 & 41 & 12 \\
\hline LDA responders, $\mathrm{N}$ & $\mathbf{7 9}$ & $\mathbf{6 9}$ & $\mathbf{6 6}$ & $\mathbf{6 3}$ & $\mathbf{5 9}$ & $\mathbf{5 7}$ & $\mathbf{4 7}$ & $\mathbf{3 5}$ & $\mathbf{8}$ \\
\hline LDA to DAS28 $2.6(\mathrm{n})$ & 40 & 41 & 45 & 47 & 42 & 40 & 30 & 23 & 3
\end{tabular}

DMARD-IR population; Figure 2B), the absolute numbers of responders and good responders (i.e., ACR50, ACR70) in particular increased. The proportion of patients with ACR20 response at Week 12 who then had ACR50/70 responses at later timepoints remained stable or continued to increase until Week 192 in the NE/NF MTX group (Figure 3A) and until Week 216 in the DMARD-IR (Figure 3B) and TNF-IR groups (Figure 3C). Mean SJC and TJC counts decreased over time in the NE/NF MTX, DMARD-IR, and TNF-IR groups (Figure 4). The largest reduction occurred between baseline and Week 24, during which SJC and TJC values decreased by about 50\% (SJC range, $48.7 \%-59.5 \%$; TJC range, $47.1 \%-55.3 \%$ ). Thereafter, SJC and TJC values decreased slightly through Week 120 and then remained stable.

Rates of LDA and DAS28 remission increased until Week 84 for both LDA $(\mathrm{n}=312)$ and DAS28 remission

B) DMARD-IR Patients

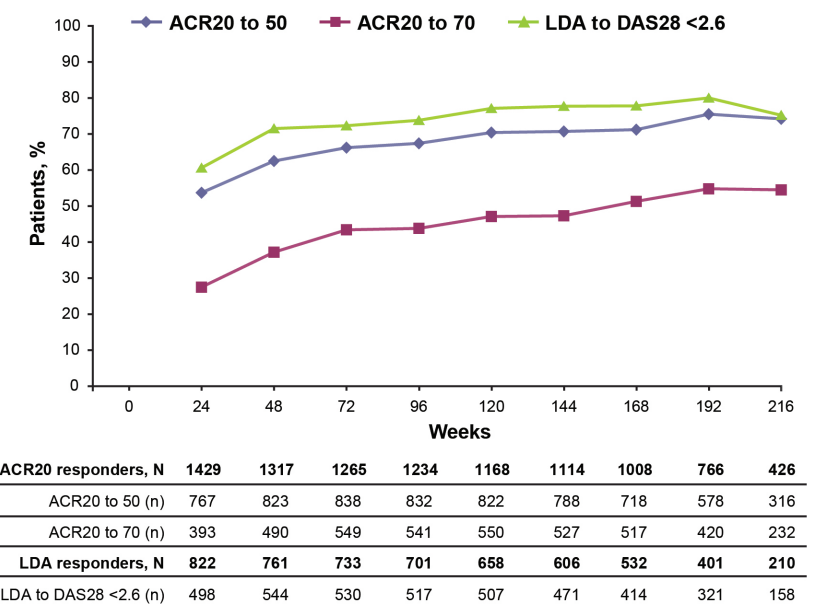


A) Mean Tender Joint Count \pm SEM

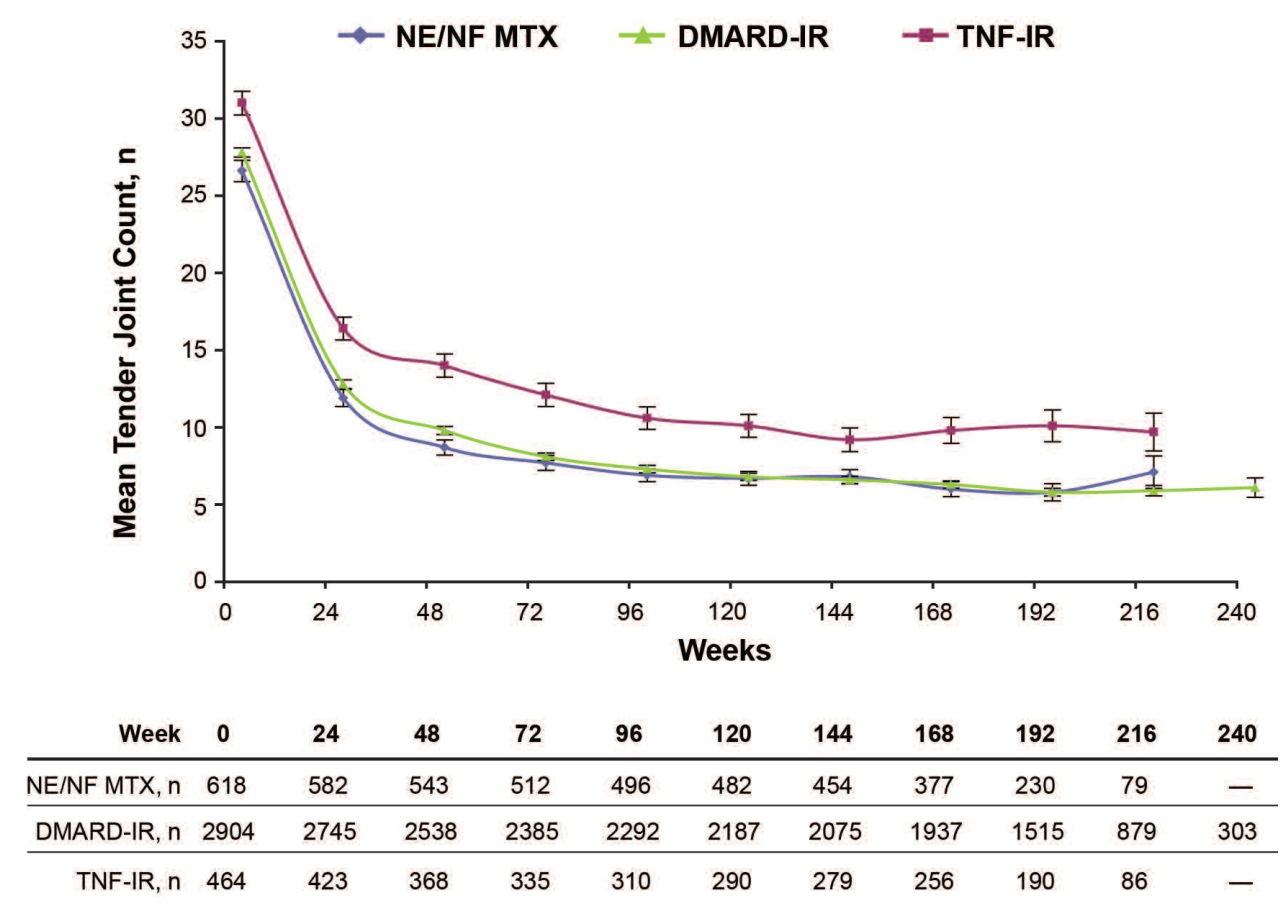

\section{B) Mean Swollen Joint Count \pm SEM}

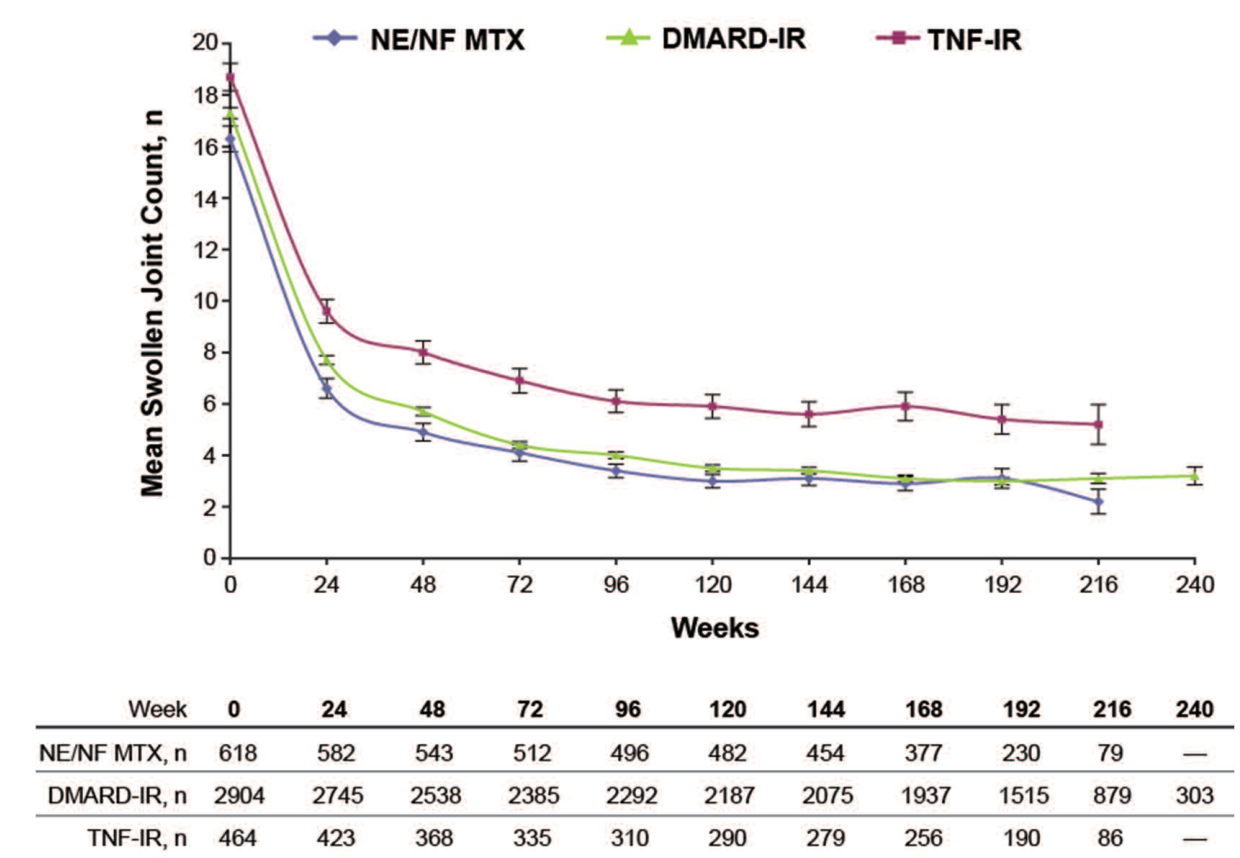

Figure 4. Summary of (A) tender joint count (68) and (B) swollen joint count (66) over time by treatment group. Tender and swollen joint count data are shown only for weeks containing $\geq 10 \%$ of patients originally included in each treatment group at baseline. Last observation carried forward was used for missing swollen or tender joint counts. Analysis was performed in successful completers, defined as patients who reached each timepoint. Numbers of patients with assessments decreased over time because some patients had not yet reached later assessments or had withdrawn. Patients who withdrew were classified as missing, and missing data were excluded from summary statistics. DMARD: disease-modifying antirheumatic drug; IR: inadequate response; MTX: methotrexate; NE/NF: never exposed/never failed; SEM: standard error of the mean; TNF: tumor necrosis factor. 
$(n=243)$ in the NE/NF MTX group, until Week 72 for LDA $(n=155)$, and until Week 84 for DAS28 remission $(n=124)$ in the TNF-IR group. In the DMARD-IR group, rates increased until Week 132 for LDA $(n=1369)$ and until Week 120 for DAS28 remission $(n=1088$; Figure 5). At the end of the evaluable period, $75.0 \%$ (69/92) of patients in the NE/NF MTX group, $74.0 \%(330 / 446)$ in the DMARD-IR group, and $57.4 \%(31 / 54)$ in the TNF-IR group had LDA. Further, $57.6 \%(53 / 92)$ of patients in the NE/NF MTX group, $61.2 \%(273 / 446)$ in the DMARD-IR group, and $35.2 \%(19 / 54)$ in the TNF-IR group achieved DAS28 remission. Two-thirds or more of patients in each group with LDA at Week 12 went on to achieve DAS remission at Week 192: $81.4 \%(48 / 59)$ of patients in the NE/NF MTX group, $80.0 \%(321 / 401)$ of patients in the DMARD-IR group, and $65.7 \%(23 / 35)$ of patients in the TNF-IR group (Figure 3). Longterm response maintenance for individual patients was assessed at the latest time with sufficient patients for analysis; Week 204 was chosen as the last point, when $>100$ patients were available for analysis in each group. By Week 204, 18.0\% (27/150) in the NE/NF MTX group, $24.8 \%$ (297/1197) in the DMARD-IR group, and $12.3 \%$ (17/138) in the TNF-IR group maintained DAS28 remission continuously for at least 48 weeks.

Disease remission was also calculated using both definitions established by the ACR/EULAR committee as a posthoc exploratory analysis ${ }^{15}$. For the all-exposed population overall, the proportion of patients who attained disease remission was $16.5 \%(172 / 1044)$ according to the Boolean definition and 22.7\% (237/1044) according to the SDAI definition at Week 216. The proportion of patients who attained disease remission (Boolean criteria) increased from baseline, peaked between 132 and 180 weeks, and then decreased slowly thereafter (Figure 6). Peak values were $26.5 \%(125 / 472)$ in the NE/NF MTX group at Week 132, $13.0 \%(36 / 276)$ in the TNF-IR group at Week 156, and $19.7 \%$ (346/1755) in the DMARD-IR group at Week 180. At the last evaluable timepoint, proportions of patients who attained disease remission were $19.0 \%$ (15/79; Week 216), 8.1\% (7/86; Week 216), and 14.9\% (45/303; Week 240), respectively (Figure 6, Table 3). In the all-control population, rates of disease remission at Week 24 were $1.7 \%$ $(26 / 1551)$ in the placebo group, $3.9 \%(30 / 773)$ in the 4 $\mathrm{mg} / \mathrm{kg}$ TCZ group, and $6.2 \%(116 / 1862)$ in the $8 \mathrm{mg} / \mathrm{kg} \mathrm{TCZ}$ group, according to the Boolean definition, and they were $2.3 \%$ (36/1551), 5.2\% (40/773), and 7.9\% (148/1862), respectively, according to the SDAI definition.

Categorical change from baseline in HAQ-DI scores (improved, $\leq 0.5$; unchanged, $>-0.5$ to $<0.5$; or worsened, $\geq 0.5$ ) was evaluated up to Week 192 in NE/NF MTX patients and up to Week 216 in DMARD-IR and TNF-IR patients. HAQ-DI scores improved or remained unchanged in the vast majority (> 95\%) of patients. Proportions of patients with improvement in HAQ-DI at the end of the assessment period were higher in NE/NF MTX patients $(63.0 \%, 114 / 181)$ and DMARD-IR patients $(56.3 \%$, 339/602) at Weeks 192 and 216, respectively, than in TNF-IR patients $(38.7 \%, 24 / 62)$ at Week 216 . The proportion of patients with HAQ-DI scores that had worsened at the end of the assessment period was relatively low in all groups: $2.8 \%(5 / 181)$ of NE/NF MTX patients, $1.8 \%(11 / 602)$ of DMARD-IR patients, and $4.8 \%(3 / 62)$ of TNF-IR patients.

\section{DISCUSSION}

We describe the most comprehensive account to date of prolonged treatment with TCZ of patients (> 4000) with moderate to severe active RA for up to 4.6 years. Results confirm that TCZ has a consistent longterm safety profile in patients with moderate to severe RA. In addition, efficacy among patients who continued TCZ treatment was sustained.

Compared with the TCZ RCT and the integrated safety analysis reported by Schiff, et $a l^{13}$, no new safety signals were identified in the present analysis. Consistent with the previous report ${ }^{13}$ and with what is expected for an RA biologic agent, the most common $\mathrm{AE}$ and SAE were infections. As with rates of AE, overall rates of SAE were similar among the 3 treatment groups in the all-control population and during the first 12 months of treatment in the longer-term all-exposed population. No further evidence of an increase in frequency or type of the most common $\mathrm{AE}$ and SAE was noted with prolonged exposure to TCZ. Similarly, the frequency of AE leading to withdrawal or dose modification/interruption, AE of severe intensity, and deaths remained stable or decreased with prolonged exposure to TCZ.

These results also show a sustained and durable response in various measures of clinical and functional efficacy through 4.6 years of TCZ treatment. Most measures of clinical efficacy, including ACR20/50/70 responses, TJC and SJC, ACR core set components, and LDA or DAS28 remission, were sustained across populations and over time. Patients with prolonged exposure to TCZ appeared to improve over time in clinical and functional efficacy measures that typically are more difficult to achieve. For example, proportions of patients with ACR20 response at Week 12 who then had ACR50/70 responses at later timepoints remained stable or continued to increase over time. Two-thirds or more of patients with LDA at Week 12 went on to achieve DAS remission at Week 192, and many patients - up to $63 \%$ in the NE/NF MTX group - had improved HAQ-DI scores $(\leq-0.5)$. These results suggest that the improvement in clinical response to TCZ is durable over time.

A joint committee of ACR and EULAR members has published 2 new, more stringent standardized definitions of 


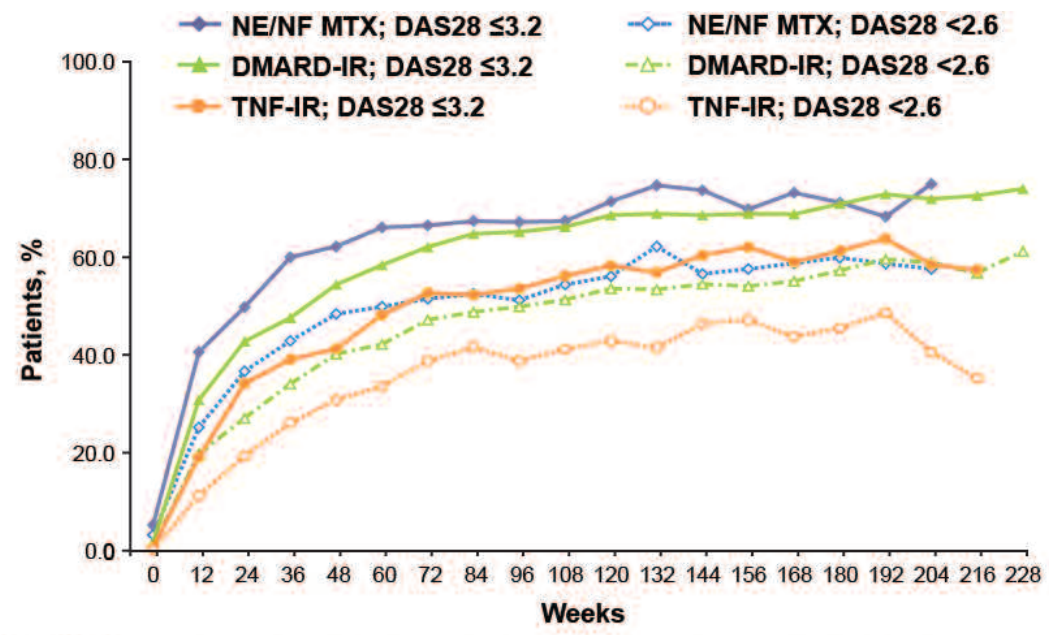

NEINF MTX pts wl
valid assessments, $N$,

$\begin{array}{llllllllllllllllllll}\text { N } & 616 & 603 & 556 & 515 & 502 & 481 & 472 & 463 & 461 & 445 & 440 & 423 & 410 & 377 & 325 & 257 & 167 & 92 & \end{array}$ $\begin{array}{lllllllllllllllllll}\text { DAS28 } \leq 3.2, n & 32 & 245 & 277 & 309 & 312 & 318 & 314 & 312 & 310 & 300 & 314 & 316 & 302 & 263 & 238 & 183 & 114 & 69\end{array}$ $\begin{array}{llllllllllllllllllll}\text { DAS28<2.6, n } & 20 & 152 & 204 & 221 & 243 & 240 & 243 & 243 & 236 & 242 & 247 & 263 & 232 & 217 & 191 & 154 & 98 & 53 & \end{array}$

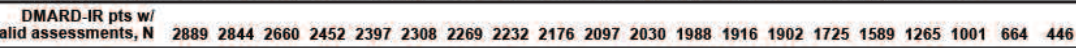
$\begin{array}{lllllllllllllllllllllll}\text { DAS28 } \leq 3.2, \mathrm{n} & 50 & 876 & 1138 & 1168 & 1303 & 1348 & 1408 & 1447 & 1419 & 1389 & 1393 & 1369 & 1315 & 1311 & 1187 & 1127 & 922 & 720 & 482 & 330\end{array}$ $\begin{array}{llllllllllllllllllllll}\text { DAS28 }<2.6, n & 23 & 564 & 722 & 836 & 963 & 975 & 1070 & 1090 & 1086 & 1076 & 1088 & 1062 & 1044 & 1029 & 951 & 911 & 754 & 590 & 377 & 273\end{array}$

\begin{tabular}{cllllllllllllllllllll}
\hline $\begin{array}{c}\text { TNF-IR pts w/ } \\
\text { valid assessments, N }\end{array}$ & 462 & 446 & 392 & 353 & 334 & 301 & 294 & 298 & 278 & 267 & 254 & 253 & 250 & 248 & 222 & 191 & 152 & 106 & 54
\end{tabular} $\begin{array}{lllllllllllllllllllllllll}\text { DAS28 } \leq 3.2, \mathrm{n} & 3 & 85 & 134 & 138 & 138 & 145 & 155 & 156 & 149 & 150 & 148 & 144 & 151 & 154 & 131 & 117 & 97 & 62 & 31\end{array}$ $\begin{array}{llllllllllllllllllll}\text { DAS28 }<2.6, \mathrm{n} & 1 & 50 & 76 & 92 & 103 & 101 & 114 & 124 & 108 & 110 & 109 & 105 & 116 & 117 & 97 & 87 & 74 & 43 & 19\end{array}$

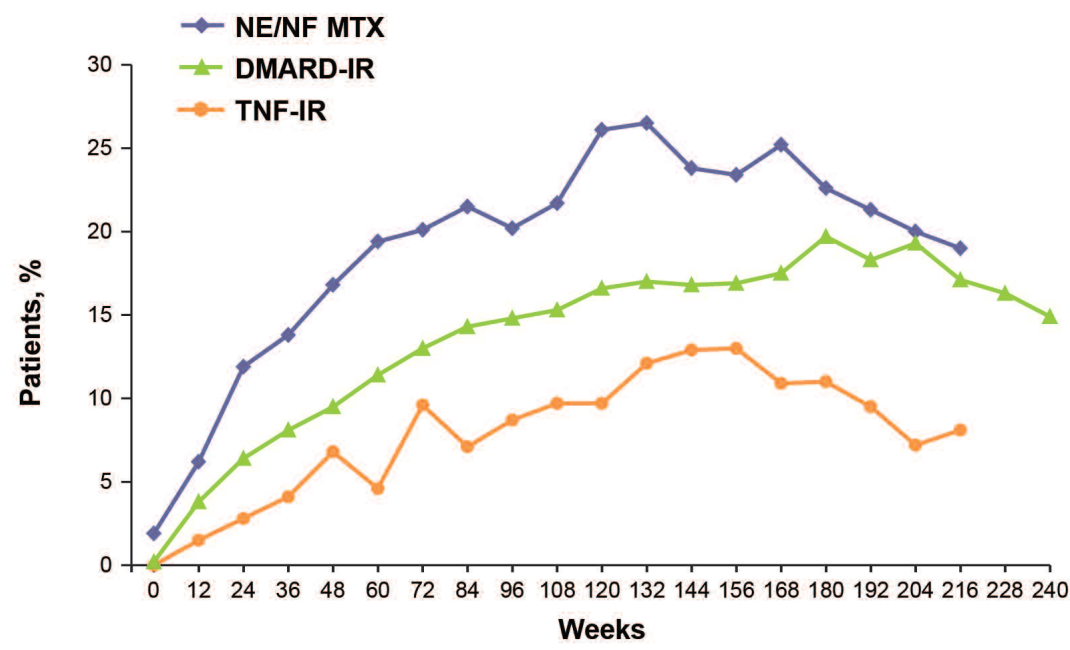

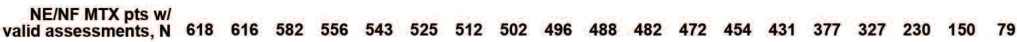
$\begin{array}{lllllllllllllllllllll}\text { Remission, } \mathrm{n} & 12 & 38 & 69 & 77 & 91 & 102 & 103 & 108 & 100 & 106 & 126 & 125 & 108 & 101 & 95 & 74 & 49 & 30 & 15\end{array}$

\begin{tabular}{c} 
DMARD-IR pts w/ \\
valid assessments, N 29042899274726422538245723852344229222382187212920752031 \\
\hline
\end{tabular} $\begin{array}{llllllllllllllllllllll}\text { Remission, } \mathrm{n} & 6 & 110 & 175 & 214 & 242 & 281 & 310 & 336 & 339 & 343 & 364 & 361 & 348 & 343 & 339 & 346 & 278 & 231 & 150 & 95 & 45\end{array}$

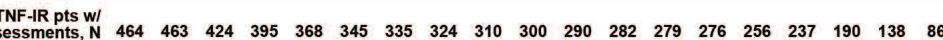

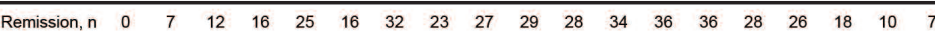

Figure 5. Patients who achieved low disease activity (LDA; DAS28 $\leq 3.2$ ) or DAS28 remission (DAS28 < 2.6) during longterm treatment with TCZ. Data are shown only for weeks containing $\geq 10 \%$ of patients originally included in each group at baseline. Last observation carried forward was used for tender and swollen joint counts. No imputation was used for erythrocyte sedimentation rate or for Patient Global Assessment of Disease Activity score. Numbers of patients with assessments decreased over time because some patients had not yet reached later assessments or had withdrawn. DAS28: Disease Activity Score in 28 joints; DMARD: diseasemodifying antirheumatic drug; IR: inadequate response; MTX: methotrexate; NE/NF: never exposed/never failed; TNF: tumor necrosis factor; TCZ: tocilizumab.
Figure 6. Patients who achieved remission according to ACR/EULAR Boolean criteria. Remission is achieved if the patient has no more than 1 tender joint, no more than 1 swollen joint, CRP no greater than $1 \mathrm{mg} / \mathrm{dl}$, and Patient Global Assessment of Disease Activity score no greater than $1 \mathrm{~cm}$. Data are shown only for weeks containing $\geq 10 \%$ of patients originally included in each group at baseline. Last observation carried forward was used for tender and swollen joint counts. Nonresponder imputation was used for missing CRP and Patient Global Assessment score. Numbers of patients with assessments decreased over time because some patients had not yet reached later assessments or had withdrawn. ACR: American College of Rheumatology; CRP: C-reactive protein; DMARD: disease-modifying antirheumatic drug; EULAR: European League Against Rheumatism; IR: inadequate response; MTX: methotrexate; NE/NF: never exposed/never failed; TNF: tumor necrosis factor. 
Table 3. ACR/EULAR remission rates and components at the last evaluable timepoint in the efficacy population. Remission is achieved if the patient has no more than 1 tender joint, no more than 1 swollen joint, CRP no greater than $1 \mathrm{mg} / \mathrm{dl}$, and Patient Global Assessment of Disease Activity score no greater than 1. Last evaluable timepoint is the last week with $\geq 10 \%$ of patients originally included in each group at baseline. Last observation carried forward was used for TJC and SJC. Nonresponder imputation was used for missing CRP and Patient Global Assessment Disease Activity score.

\begin{tabular}{lccc}
\hline Criterion, $\mathrm{n}(\%)$ & $\begin{array}{c}\text { NE/NF MTX, } \\
\mathrm{n}=618\end{array}$ & $\begin{array}{c}\text { DMARD-IR } \\
\mathrm{n}=2904\end{array}$ & $\begin{array}{c}\text { TNF-IR, } \\
\mathrm{n}=464\end{array}$ \\
\hline $\begin{array}{l}\text { Last evaluable timepoint } \\
\text { No. patients with efficacy assessment at timepoint }\end{array}$ & $\begin{array}{c}\text { Week } 216 \\
\text { TJC } \leq 1\end{array}$ & $\begin{array}{c}\text { Week } 240 \\
303\end{array}$ & $\begin{array}{c}\text { Week 216 } \\
86\end{array}$ \\
SJC $\leq 1$ & $39(49.4)$ & $170(56.1)$ & $30(34.9)$ \\
CRP $\leq 1$ mg/dl & $56(70.9)$ & $188(62.0)$ & $39(45.3)$ \\
Patient global assessment of disease activity score & $44(55.7)$ & $200(66.0)$ & $60(69.8)$ \\
$\quad$ & & & \\
Remission (all $\leq 1)$ & $18(22.8)$ & $58(19.1)$ & $14(16.3)$ \\
Remission (SDAI $\leq 3.3)$ & $15(19.0)$ & $45(14.9)$ & $7(8.1)$ \\
\hline
\end{tabular}

ACR: American College of Rheumatology; CRP: C-reactive protein; DMARD: disease-modifying antirheumatic drug; EULAR: European League Against Rheumatism; IR: inadequate response; MTX: methotrexate; NE/NF: never exposed/never failed; SDAI: Simplified Disease Activity Index; SJC: swollen joint count; TJC: tender joint count; TNF: tumor necrosis factor.

disease remission for use in RA clinical trials ${ }^{15}$. The first definition is Boolean-based and requires that patients have TJC, SJC, CRP (mg/dl), and Patient Global Assessment (1-10 scale) of Disease Activity score $\leq 1$ at any time. The second definition is index-based and requires that patients have SDAI scores $\leq 3.3$ at any time. Overall, the proportions of patients who attained disease remission were $16.5 \%$ (Boolean) and $22.7 \%$ (SDAI), indicating that about 1 of 5 patients who tolerated TCZ and opted into the extension trial achieved disease remission by these criteria for up to 216 weeks. In each of the efficacy groups, the proportion of patients who attained disease remission decreased slightly with time. Contributions of the individual components used to calculate ACR/EULAR remission rates may provide some insight into attainment of these remission rates. At most timepoints, improvements in markers of inflammation (i.e., CRP, SJC, and TJC) were significant; however, attainment of Patient Global Assessment of Disease Activity score was lower in comparison and therefore became the rate-limiting component for attainment of remission. In contrast, Patient Global Assessment of Disease Activity score has a very small effect on the calculation of DAS28 $<2.6$, and thus is a minor contributing factor. On the other hand, ESR has a very significant effect on DAS28 ${ }^{20}$; therefore, agents that profoundly inhibit ESR response will lead to higher DAS28 remission rates.

Although cumulative analyses of safety and efficacy provide a more comprehensive view of a drug's clinical profile than do individual studies, several important limitations must be considered when longterm data are interpreted. Because longterm studies follow patients for several years, patient numbers decrease over time. For example, the proportion of TNF-IR patients with LDA who then attained
DAS remission decreased from $65.7 \%$ at Week 192 to $37.5 \%$ at Week 216, possibly because the sample size at Week 216 was only 8 (Figure 3C). Patients who participate and continue treatment in open-label extensions of clinical trials typically experience sufficient clinical and functional improvement and acceptable tolerability. Therefore, safety and efficacy measurements may be more favorable than those observed in short-term studies (e.g., 24 or 52 weeks).

Another caveat is that treatment modifications were permitted according to predefined criteria in the clinical trial protocols. Thus, original treatment assignment may be less reflective of treatment received over time. For example, investigators were permitted to modify or add a DMARD for safety or efficacy reasons. Treatment modifications made during the course of the study could have affected the safety and efficacy data. Additionally, the ways in which data are handled for short-term and longterm efficacy analyses differ. For example, in the 24-week analyses, missing data were imputed conservatively as nonresponders because those patients are more likely to withdraw for safety reasons or lack of efficacy. In longterm extensions, however, missing data are not imputed (i.e., only patients with observed data are reported) because other factors (e.g., inconvenience of longterm study participation, relocation) are likely to influence a patient's decision to withdraw. Finally, in our study, efficacy was evaluated only up to points at which $\geq 10 \%$ of patients initially randomly assigned to the treatment group remained in the study. These differences preclude direct comparisons between cumulative longterm efficacy analyses and the 24-week and 52-week randomized trials.

Data from this longterm cumulative safety and efficacy analysis demonstrate that TCZ has a safety profile 
consistent with previous observations with no new safety signals and that it provides durable efficacy for up to 4.6 years of treatment in patients with RA.

\section{ACKNOWLEDGMENT}

The authors acknowledge Maribeth Bogush, PhD, and Sara Duggan, PhD, who provided writing services on behalf of F. Hoffmann-La Roche Ltd.

\section{REFERENCES}

1. Lee DM, Weinblatt ME. Rheumatoid arthritis. Lancet 2001;358:903-11

2. Scott DL. Radiological progression in established rheumatoid arthritis. J Rheumatol Suppl. 2004 Mar;69:55-65.

3. Welsing PM, van Gestel AM, Swinkels HL, Kiemeney LA, van Riel PL. The relationship between disease activity, joint destruction, and functional capacity over the course of rheumatoid arthritis. Arthritis Rheum 2001;44:2009-17.

4. Salaffi F, Carotti M, Gasparini S, Intorcia M, Grassi W. The health-related quality of life in rheumatoid arthritis, ankylosing spondylitis, and psoriatic arthritis: A comparison with a selected sample of healthy people. Health Qual Life Outcomes 2009;7:25.

5. Lundkvist J, Kastang F, Kobelt G. The burden of rheumatoid arthritis and access to treatment: Health burden and costs. Eur J Health Econ 2008;8:S49-60.

6. Mihara M, Kasutani K, Okazaki M, Nakamura A, Kawai S, Sugimoto M, et al. Tocilizumab inhibits signal transduction mediated by both mIL-6R and sIL-6R, but not by the receptors of other members of IL-6 cytokine family. Int Immunopharmacol 2005;5:1731-40.

7. Smolen JS, Beaulieu A, Rubbert-Roth A, Ramos-Remus C, Rovensky J, Alecock E, et al. Effect of interleukin-6 receptor inhibition with tocilizumab in patients with rheumatoid arthritis (OPTION study): A double-blind, placebo-controlled, randomised trial. Lancet 2008;371:987-97.

8. Genovese MC, McKay JD, Nasonov EL, Mysler EF, da Silva NA, Alecock E, et al. Interleukin-6 receptor inhibition with tocilizumab reduces disease activity in rheumatoid arthritis with inadequate response to disease-modifying antirheumatic drugs: The tocilizumab in combination with traditional disease-modifying antirheumatic drug therapy study. Arthritis Rheum 2008;58:2968-80.

9. Emery P, Keystone E, Tony HP, Cantagrel A, van Vollenhoven R, Sanchez A, et al. IL-6 receptor inhibition with tocilizumab improves treatment outcomes in patients with rheumatoid arthritis refractory to anti-tumour necrosis factor biologicals: Results from a 24-week multicentre randomised placebo-controlled trial. Ann Rheum Dis 2008;67:1516-23.
10. Jones G, Sebba A, Gu J, Lowenstein MB, Calvo A, Gomez-Reino $\mathrm{JJ}$, et al. Comparison of tocilizumab monotherapy versus methotrexate monotherapy in patients with moderate to severe rheumatoid arthritis: The AMBITION study. Ann Rheum Dis 2010;69:88-96.

11. Kremer JM, Blanco R, Brzosko S, Burgos-Vargas R, Halland AM, Vernon E, et al. Tocilizumab inhibits structural joint damage in rheumatoid arthritis patients with inadequate responses to methotrexate: Results from the double-blind treatment phase of a randomized placebo-controlled trial of tocilizumab safety and prevention of structural joint damage at one year. Arthritis Rheum 2011;63:609-21.

12. Nishimoto N, Miyasaka N, Yamamoto K, Kawai S, Takeuchi T, Azuma J. Long-term safety and efficacy of tocilizumab, an anti-interleukin-6 receptor monoclonal antibody, in monotherapy, in patients with rheumatoid arthritis (the STREAM study): Evidence of safety and efficacy in a 5-year extension study. Ann Rheum Dis 2008;68:1580-4.

13. Schiff MH, Kremer JM, Jahreis A, Vernon E, Isaacs JD, van Vollenhoven RF. Integrated safety in tocilizumab clinical trials Arthritis Res Ther 2011;13(R141):1-13.

14. Genentech Inc. Actemra (tocilizumab) prescribing information. Genentech Inc. South San Francisco, CA: Genentech Inc.; 2010. [Internet. Accessed December 13, 2012.] Available from: www.gene.com/gene/products/information/actemra/pdf/pi.pdf

15. Felson DT, Smolen JS, Wells G, Zhang B, van Tuyl LH, Funovits J, et al. American College of Rheumatology/European League Against Rheumatism provisional definition of remission in rheumatoid arthritis for clinical trials. Ann Rheum Dis 2011;70:404-13.

16. Curtis JR, Xie F, Chen L, Spettell C, McMahan RM, Fernandes J, et al. The incidence of gastrointestinal perforations among rheumatoid arthritis patients. Arthritis Rheum 2011;63:346-51.

17. Solomon DH, Karlson EW, Rimm EB, Cannuscio CC, Mandl LA, Manson JE, et al. Cardiovascular morbidity and mortality in women diagnosed with rheumatoid arthritis. Circulation 2003;107:1303-7

18. Watson DJ, Rhodes T, Guess HA. All-cause mortality and vascular events among patients with rheumatoid arthritis, osteoarthritis, or no arthritis in the UK General Practice Research Database. J Rheumatol 2003;30:1196-202.

19. Solomon DH, Goodson NJ, Katz JN, Weinblatt ME, Avorn J, Setoguchi S, et al. Patterns of cardiovascular risk in rheumatoid arthritis. Ann Rheum Dis 2006;65:1608-12.

20. Fransen J, van Riel PL. DAS remission cut points. Clin Exp Rheumatol 2006;24:S29-32. 